\title{
GEO-ENGINEERING TO CONFINE CLIMATE CHANGE: IS IT AT ALL FEASIBLE?
}

\author{
An Editorial Comment
}

\section{Introduction}

Paul Crutzen (2006) has suggested a research initiative to consider whether it would be feasible to artificially enhance the albedo of the planet Earth to counteract greenhouse warming. The enhancement of albedo would be achieved by intentionally injecting sulfur into the stratosphere. The rational for proposing the experiment is the observed cooling of the atmosphere following the recent major volcanic eruptions by El Chichon in 1984 and Mount Pinatubo in 1991 (Hansen et al., 1992). Although I am principally not against a research initiative to study such a potential experiment, I do have important reservations concerning its general feasibility. And its potential feasibility, I believe, must be the key motivation for embarking on such a study. Here I will bring up three major issues, which must be more thoroughly understood before any geo-engineering of climate could be considered, if at all. The three issues are (i) the lack of accuracy in climate prediction, (ii) the huge difference in timescale between the effect of greenhouse gases and the effect of aerosols and (iii) serious environmental problems which may be caused by high carbon dioxide concentration irrespective of the warming of the climate.

\section{How Predictable is Climate Change?}

As a central line of thought in Crutzen's paper, is conceptually an energy balance view on climate change where the warming from increasing greenhouse gases and the cooling from sulfate aerosols broadly are controlling the climate and this also on a relatively short time scale. With this paradigm of the cause of climate change these two agents in combination with land surface changes have then virtually regulated the climate over the last several decades and this even as is indicated on a regional scale (Chapin III et al., 2005). An increase in aerosols in the 1950s through the 1970s is then seen as the cause of the minor cooling following the relative warm decades in the 1930s and 1940s. And along the same line of thought the present reduced aerosol emission is being interpreted as a potential cause of the acceleration of global warming in recent years (Andreae et al., 2005). However, recent model experiments indicate that the Earth's climate system is exposed to considerable internal variations, which essentially are of chaotic nature (Bengtsson, 2001), although some phenomena are predictable for periods of several months to 
a year or so (Shukla, 1998). In certain regions of the world, Europe (Bengtsson et al., 2006) and the Arctic (Johannessen et al., 2004; Bengtsson et al., 2004) internal atmospheric and ocean modes actually dominate the climate. There are strong indications that the variations of climate during the last century were caused by internal fluctuations superimposed on a increasingly warming trend driven by a net positive and gradually stronger forcing of anthropogenic nature (Delworth and Knutson, 2000).

The second point to make is that our understanding of the effects on aerosols on climate is less well understood than the greenhouse gases. Aerosols are not well mixed and interact with clouds in a complex way, where many questions are still open as we lack detailed empirical data. In addition, the role of clouds in regulating the climate under changed forcing conditions is not yet known with sufficient details. Present climate models are highly parameterized and the processes regulating the interaction of clouds, aerosols and radiation through the depth of the atmosphere are highly tuned. We do not yet know for sure to what extent we overestimate the feedback effect from the greenhouse gases and thus need the aerosols as compensation or whether we underestimate the effect of the greenhouse gases and thus the effect of aerosols is less significant (Rodhe et al., 2000).

How well are we presently able to simulate climate change? The IPCC 3rd assessment gave a range of 1.3-4.5 C for different model temperature assessments (Cubasch et al., 2001) for the 30-year average 2071-2100 relative to 1961-1990 using the same IPCC emission scenario A2 (including greenhouse gases and aerosols). And these are global average values! The main cause to this wide range is differences in modeling feedback processes, mainly related to the handling of clouds, but also due to differences in the energy exchange with the oceans and the land surfaces. The very wide range in climate response reported by (Stainforth et al., 2005) (a factor of 10) is presumably an overestimation due to the fact that some model versions having extreme response appear to be inconsistent vis-à-vis the interaction between water vapor and clouds. The experiments indicate nevertheless the huge sensitivity of models to feedback processes. It is interesting to note that the wide range of climate response has not narrowed in spite of active modeling work for more than a quarter of a century (Charney et al., 1979) In fact it cannot be ruled out that the range will further widen in the next IPCC assessment in 2007, when we expect to have results from more comprehensive models including carbon feedbacks with the biosphere. It should be stressed that these results have nothing to do with different assumptions on aerosols but mainly with the way models handle non-resolvable processes and natural feedback processes in the climate system.

Therefore, at least on time scales shorter than a century or so, internal climate dynamics may significantly hide the effect of robust forcing agents and in particular so in some regions of the world. The magnitude of the model response to forcing is likely to vary in amplitude by at least a factor of 2-3 for the time we presently confidently can overlook. The main reasons are insufficient knowledge of the climate system and lack of resources to model it accurately enough. 


\section{The Time Scale of Climate Change}

While an enhanced albedo will reduce surface temperature within a time scale of a year or so, carbon dioxide will affect climate on a much longer time scale. Archer et al. (1997) have calculated the time scales for the neutralization of fossil fuel $\mathrm{CO}_{2}$. Because of the limited capacity of future biospheric uptake the future fate of fossil fuel $\mathrm{CO}_{2}$ is therefore largely an oceanographic problem. As shown by Archer et al. (ibid) the reduction will occur in three different time scales having the characteristic time of several hundred years, 5.5-6.8 kyr and 200kyr, respectively. Although the dissolution into ocean water sequesters $70-80 \%$ of the $\mathrm{CO}_{2}$ on a time scale of several hundred years a minor part remains until the entire fossil fuel release is consumed by weathering of basic igneous rocks on the longest of these time scales. For this reason it follows that the artificial release of sulfate aerosols is a commitment of at least several hundred years. A cessation of the intentional sulfate emission of 1-2 Mton/year will in a short period of time lead to a return to the unfavorable conditions and a renewed warming of the planet. The additional complication is that a temporary solution may weaken the incentive to reduce the $\mathrm{CO}_{2}$ emission and therefore increase the atmospheric concentration further.

\section{Other Problems with High $\mathrm{CO}_{2}$ Concentration}

The effect of an increase of $\mathrm{CO}_{2}$ on the terrestrial biosphere is complex. On one hand, and assuming sufficient nourishment is available, it may favor additional growth of plants and possibly also to a more economical use of water. On the other hand, it will imply changes in the competitive balances between different plants as certain types of biomes may be more favored, including weeds, and others less favored with a higher $\mathrm{CO}_{2}$ concentration. The effect of this needs to be better understood.

However, the greatest worry of high $\mathrm{CO}_{2}$ concentrations is presumably the effect on ocean acidification and consequences for the ocean biosphere (Doney, 2006). The oceans so far have absorbed about half of all the fossil carbon released to the atmosphere since the beginning of the industrial revolution. Carbon dioxide combines with water to form carbonic acid as well as ions of hydrogen, carbonate and bicarbonate. The absorption of carbon dioxide has already caused the $\mathrm{pH}$ of present surface water to be about 0.1 lower (less alkaline) than it was in pre-industrial times. It is estimated that $\mathrm{pH}$ will fall an additional 0.3 unit by 2100 assuming the anticipated increase in the $\mathrm{CO}_{2}$ emission. It is suggested that this will be the lowest value in 300 million years (Caldeira and Wickett, 2003).

Polar waters, particularly those surrounding Antarctica, are expected to become under-saturated with respect to aragonite, making it difficult for organisms, such as pteropods to make aragonite and causing aragonite already formed to dissolve. Another concern is the outlook for coral reefs. Many coral reefs, which already 
are in decline, may be pushed into nonexistence due to further ocean acidification (Doney, 2006).

\section{Concluding Remarks}

Let us now undertake the following Gedankenexperiment. We have reached a state of around $600 \mathrm{ppm}$ equivalent $\mathrm{CO}_{2}$ concentration sometime around the middle of the century with a global average temperature of some $2 \mathrm{~K}$ higher compared to now. There is a general agreement that this warming cannot be due to natural processes and there are no indications that the warming can be due to other possible external causes. A further warming of another $2 \mathrm{~K}$ towards the end of the century is considered as highly possible unless greenhouse emission is significantly reduced. At this moment it is decided to undertake a geo-engineering project as outlined in Crutzen's paper by reducing planetary albedo by artificially emitting sulfate aerosols into the atmosphere.

An obvious question to ask is how long time it may take before the greenhouse gas concentration in the atmosphere has been reduced to a tolerable level, as this will determine the length of time the geo-engineering project will have to be continued until an amount of say some 600 Gton of carbon has been removed from the atmosphere to be dissolved into the oceans (Archer et al., 1997). Unfortunately this is not a fast process. As calculated by (Archer et al., ibid) to dissolve some $80 \%$ will take of the order of some 500 years. So the geo-engineering project will have to be undertaken for this period of time or longer, as further emission of greenhouse gases are likely to emitted in the mean time since the aerosol experiment will be seen as the solution and no major efforts may be seen as required to reduce $\mathrm{CO}_{2}$ emission. However, as soon as we cease to emit sulfate aerosols into the stratosphere the climate will move back to the state determined by the greenhouse gas concentration as fast as the planet has warmed up after a major volcanic eruption such as the one of Mount Pinatubo (Hansen et al., 1992). And this will take at most a few years.

I leave it to the reader to ponder over the feasibility to undertake a joint experiment to control the Earth's climate, which may have to last for the length of perhaps a millennium. And the fact that the efforts will be of little use unless we continue the aerosol emission without interruptions. And, finally, as the experiment is conducted we will not be able to convincingly demonstrate that it actually works unless we have collected validation data for at least several decades towards the background of natural climate variability.

Needless to say, the lack of suitable energy for many parts of the world is an enormous challenge, perhaps more important and more urgent to address than even the climate problem. The obvious approach in my view is to pursue the development of alternative systems to fossil fuel for energy generation combined with more efficient use of energy and sequestration of carbon dioxide. There are presently 
many favorable developments of more advanced and safer systems for nuclear energy generation including encouraging progress in fusion energy. Such systems can also be combined with the generation of hydrogen gas for transport applications (http://gif.inel.gov/roadmap/). Photovoltaic techniques and solar energy in general have great potentials in particular in the developing countries. Furthermore, there are very promising development in much more economical use of energy such as efficient heat pumps for temperature regulations (warming as well as cooling) in buildings and hybrid car engines. What are needed are a more positive attitude towards new technology and more long-term commitments towards advanced technology. Perhaps the frightening prospect of a geo-engineering project to artificially change the Earth's albedo would activate the creative mind of mankind to find sensible solutions of the energy problem.

So in conclusion, I do consider it more feasible to succeed in solving the world's energy problem, which is the main cause to the present concern about climate change, than to successfully manage a geo-engineering experiment on this scale and magnitude, which even if it works is unable to solve all problems with the very high concentration of greenhouse gases in the atmosphere.

\section{References}

Andreae, M. O., Jones, C. D., and Cox, P. M.: 2005, 'Strong present-day aerosol cooling implies a hot future', Nature 435, 1187-1190.

Archer, D., Khesgi, H., and Maier-Reimer, E.: 1997, 'Multiple timescales for neutralization of fossil fuel $\mathrm{CO}_{2}$ ', Geophys. Res. Lett. 24, 405-408.

Bengtsson, L.: 2001, 'Uncertainties of global climate predictions', in Schulze, E.-D., et al. (eds.), Global Biochemical Cycles in the Climate System, Academic Press, pp. 15-30 ISBN 0-12-6312605 .

Bengtsson, L., Semenov, V., and Johannessen, O. M.: 2004, 'The early 20th century warming in the Arctic - A possible mechanism', J. Climate Oct. 2004, 4045-4057.

Bengtsson, L., Hodges, K. I., Roeckner, E., and Brokopf, R.: 2006, 'On the natural variability of the pre-industrial European Climate', Climate Dyn. 1-18, DOI: 10.1007/s00382-006-0168-y.

Caldeira, K. and Wickett, M. E.: 2003, 'Anthropogenic carbon and ocean pH', Nature 425, 365.

Charney, J. E., et al.: 1979, 'Carbon dioxide and climate: A scientific assessment', Report of an ad hoc Study Group on Carbon Dioxide and Climate. National Research Council, National Academy of Sciences.

Chapin, III, F. S. et al.: 2005, 'Role of land-surface changes in Arctic summer warming', Science 310, $657-660$

Crutzen, P. J.: 2006, 'Albedo enhancement by stratospheric sulfur injections: A contribution to resolve a policy dilemma?', Climatic Change, this issue, DOI: 10.1007/s10584-006-9101-y.

Cubasch, U., et al.: 2001, 'Projections of future climate change, chapter 9, climate change 2001: in Houghton, J. T. et al. (eds.), The Scientific Basis, Third Assessment Report of the Intergovernmental Panel on Climate Change Cambridge University Press, Cambridge, U.K. and New York, N.Y., USA, pp 525-582.

Delworth, T. L. and Knutson, T. R.: 2000, 'Simulation of early 20th century global warming', Science 287, 2246-2250.

Doney, S. C.: 2006, 'The dangers of ocean acidification', Scientific American 294(3), 38-45. 
Hansen, J., Lacis, A., Ruedy, R. and Sato, M.: 1992, 'Potential climate impact of Mount Pinatubo eruption', Geophys. Res. Lett. 19, 215-218.

Johannessen, O. M., Bengtsson, L., Alekseev, Nagurnyi, A. P., Zakharov, V. F., Bobylev, L. P., Petterson, L. H., Hasselmann, K., and Cattle, H.: 2004, 'Arctic climate change - observed and modeled temperature and sea ice', Tellus 56A, 328-341.

Rodhe, H., Charlson, R. J., and Anderson, T. L.: 2000, 'Avoiding circular logic in climate modeling', Climate Change 44, 419-422.

Shukla, J.: 1998, 'Predictability in the midst of chaos: A scientific basis for climate forecasting', Science 282, 728-731.

Stainforth, D. A., et al.: 2005, 'Uncertainty in predictions of the climate response to rising levels of greenhouse gases', Nature 433, 403-406.

Environmental Systems Science Centre

LENNART BENGTSSON

University of Reading

Max Planck Institute for Meteorology

Hamburg 